\title{
ASSESSMENT OF EXPOSURE OF ELEMENTARY SCHOOLS TO TRAFFIC POLLUTION BY GIS METHODS
}

\author{
Přemysı Štych ${ }^{1}$, Denisa Šrámková2, Martin Braniš² \\ 'Department of Applied Geoinformatics and Cartography, Faculty of Science, Charles University in Prague, Prague, Czech Republic \\ ${ }^{2}$ Institute for Environmental Studies, Faculty of Science, Charles University in Prague, Prague, Czech Republic
}

\section{SUMMARY}

Aim: The susceptibility of children to polluted air has been pointed out several times in the past. Generally, children suffer from higher exposure to air pollutants than adults because of their higher physical activity, higher metabolic rate and the resultant increase in minute ventilation. The aim of this study was to examine the exposure characteristics of public elementary schools in Prague (the capital of the Czech Republic).

Methods: The exposure was examined by two different methods: by the proximity of selected schools to major urban roads and their location within the modeled urban $\mathrm{PM}_{10}$ concentration fields. We determined average daily traffic counts for all roads within $300 \mathrm{~m}$ of 251 elementary schools using the national road network database and geographic information system and calculated by means of GIS tools the proximity of the schools to the roads. In the second method we overlapped the GIS layer of predicted annual urban $\mathrm{PM}_{10}$ concentration field with that of geocoded school addresses.

Results: The results showed that 208 Prague schools (almost $80 \%$ ) are situated in a close proximity $(<300 \mathrm{~m}$ ) of roads exhibiting high traffic loads. Both methods showed good agreement in the proportion of highly exposed schools at risk; however, we found significant differences in the locations of schools at risk determined by the two methods.

Conclusion: We argue that results of similar proximity studies should be treated with caution before they are used in risk based decision-making process, since different methods may provide different outcomes.

Key words: GIS, schools, traffic pollution, traffic density, particulate matter, health effects

Address for correspondence: P. Štych, Department of Applied Geoinformatics and Cartography, Faculty of Science, Charles University, Albertov 6, 12843 Prague 2, Czech Republic. E-mail: stych@natur.cuni.cz

http://dx.doi.org/10.21101/cejph.a4149

\section{INTRODUCTION}

It has been repeatedly documented in the scientific literature that exposure to air pollution can irritate the eyes, nose, and throat; may lower resistance to respiratory infections; aggravate the symptoms of, or worsen, lung diseases and even cause premature death $(1,2)$. One of the most important sources or ambient pollutants in industrialized countries is traffic. Attention has been recently focused on populations of sensitive individuals, e.g., on people with asthma, chronic obstructive pulmonary disease and heart disease; the elderly; and children (3-7).

Schwarz (8) and later Salvi (9) summarized the effects of air pollution on children's health, referring to a number of studies that have demonstrated the association of particulate matter (PM) with a variety of adverse health outcomes, including lung disease, asthma and other respiratory problems. In general, children are especially vulnerable to air pollution because even at rest they breathe in more air per unit of body weight than adults and their rates of deposition of particles during resting inhalation (normalized to lung surface area) are approximately $30 \%$ higher than in a group of adolescents and adults (10). In addition, the developing lungs of children may be especially vulnerable to the adverse consequences of particle inhalation (11).

The exposure of school children has been studied in many ways. The most numerous studies included direct exposure studies, e.g. the study by Janssen et al. (12). The exposure of school children has been recently assessed by means of the Geographical Information Systems (GIS) by calculating the proximity of schools to major roads. Schools are then divided into categories with higher and lower risk from exposure to car exhaust. Although this approach has been used in several studies (13-17), no such study was performed in the Central and East European countries where the number of cars has been rapidly increasing over the past two decades.

In our study we decided to characterize the exposure of public elementary schools to air pollution in Prague (the Czech capital) by two methods: the proximity to major urban roads and the modified US Environmental Protection Agency (US EPA) dispersion model (ISC2) allowing construction of GIS layers with the predicted ambient concentration fields of selected pollutants in selected areas, which may then be used for further GIS analysis. 


\section{MATERIALS AND METHODS}

\section{Study Area}

Traffic, air pollution, and school data were assembled for Prague, the Czech capital. The city is a region of $496 \mathrm{~km}^{2}$ inhabited by 1.25 million people. According to the modal split analysis available from the Czech Statistical Office, about one third of the urban transport is realized by car traffic (expressed in person-km). There are about 750,000 personal cars and vans and 250,000 small trucks registered in the Prague municipality database. The average age of car fleet in Prague is rather high (13 years). The public transport system is widespread. Of the total of 1.12 million passengers transported daily in Prague by all means of public transport, approximately 280,000 use urban busses. The whole urban area and its close surroundings may be characterized as a commercial/residential region without significant industrial activity.

\section{Geocoding of Schools}

A total of 251 elementary schools were used for the study (according to the Czech legislation, elementary schools are defined as those educating pupils from 6 to 15 years of age). Since only about $2 \%$ of Czech pupils attend private elementary schools and kindergartens, only public schools were included in our analysis. The addresses of the schools were retrieved from the Ministry of Education Youth and Sports Registry version 2.08.1 (as of 30 September 2010). At first all public schools in Prague were mapped using GIS. Schools were identified by addresses transferred from the Registry. Then the schools master file was converted to a point shape file for use in ArcGIS 9.3 Desktopthe Environmental Systems Research Institute (ESRI), Redlands, CA, and GIS software.

\section{Exposure Assessment}

Two methods for estimation of air pollution (proximity measure and $\mathrm{PM}_{10}$ concentration fields) were used to assess outdoor exposures to ambient particulate matter air pollution.

\section{Proximity Based Predictions}

In the first method, the distance between schools and the closest road segment with measured traffic density was evaluated by using the Near tool in GIS. The Near is one of the analysis tools in ArcGIS used in calculating proximity. This tool computes the distance from each point in the input feature class or layer to the nearest polyline or point in the Near feature class or layer within the maximum search radius. The nearest distance from school to road was calculated and the traffic density value of nearest road part was joined to the school attribute. The traffic density information was provided on request by the Technical section of the Prague Capital Municipality and contains a number of cars per day for all the main roads, i.e. major roads for any form of motor transport in Prague. Vector line data were provided in shapefile format. Data express traffic intensity on monitored transport network related to $24 \mathrm{~h}$ average of a normal workday in 2009. Motor traffic volumes included cars, trucks and buses.
All the public schools located within $300 \mathrm{~m}$ distance from roads were selected. For the visualization were proximity distances from each school to road segments divided into 5 buffer polygons of a specified distance: 0-50 m, 50-100 m, $100-150 \mathrm{~m}, 150-200 \mathrm{~m}$ and $200-300 \mathrm{~m}$. The traffic density was also divided into five categories $<10,000 ; 10,000-20,000$; 20,000-30,000; 30,000-40,000; and $>40,000$ cars per day. Since heavy trucks $(>6 \mathrm{t})$ are not allowed to enter the city and vehicles over $3.5 \mathrm{t}$ and $6 \mathrm{t}$ (for the historical and outer quarters, respectively) are allowed only with permission, the number of busses and lorries ( $6 \%$ of the total traffic) were included in the car counts and only one category of vehicles was used in the subsequent analysis.

\section{Predictions Based on Modeled Concentrations}

In the second method, the geocoded school GIS layer was overlaid by the $\mathrm{PM}_{10}$ annual average concentration field from 2010 (GIS layer constructed on the basis of a modified US EPA dispersion model ISC2) and categorized according to the level of pollution. Four categories of annual $\mathrm{PM}_{10}$ average concentrations $\left(<20 \mu \mathrm{g} / \mathrm{m}^{3}, 20-30 \mu \mathrm{g} / \mathrm{m}^{3}, 30-40 \mu \mathrm{g} / \mathrm{m}^{3}\right.$, and $\left.>40 \mu \mathrm{g} / \mathrm{m}^{3}\right)$ were used for the analysis. The $\mathrm{PM}_{10}$ annual average concentration field GIS layer was provided by the ATEM Company, a private subcontractor for the Prague Municipality in the field of air quality and pollutant dispersion modelling.

The air pollution dispersion model ATEM was found on the US EPA model Industrial Source Complex (ISC2). Considering the approach for calculating characteristics of the pollution, the ATEM model belongs to a group of so-called Gaussian dispersion models. The ATEM model has been used for modeling of a spread of pollutants from pollution sources and assess the air quality in accordance with requirements of the Czech Republic legislation and European Union directives.

\section{Model Comparison}

The association between proximity to streets and fields of $\mathrm{PM}_{10}$ concentrations was assessed by a multiple linear regression model with traffic density and proximity of schools as independent variables and the $\mathrm{PM}_{10}$ field of concentration for each school as a dependent variable. We hypothesized that the larger the distance of the particular school from the road, the lower the concentration of $\mathrm{PM}_{10}$. Similarly, the higher the traffic density in the school proximity, the higher the $\mathrm{PM}_{10}$ concentration at particular school location.

In the second part of this comparison, all public elementary school buildings in Prague situated within $300 \mathrm{~m}$ of distance from the nearest main road were divided into four classes ( 1 to 4) of exposure proxies according to: level of predicted particulate ambient pollution in receptor point of the dispersion model, which represent the location of the school (class 1 covers $\mathrm{PM}_{10}$ concentration $<20 \mu \mathrm{g} / \mathrm{m}^{3}$; class $2: 20-25 \mu \mathrm{g} / \mathrm{m}^{3}$; class $3: 25-30$ $\mu \mathrm{g} / \mathrm{m}^{3}$; and class $\left.4: 30-40 \mu \mathrm{g} / \mathrm{m}^{3}\right)$; the traffic density $(1:<10,000$; 2: 10,000-20,000; 3: 20,000-30,000; and 4: >30,000 cars/day); and according to the distance from the nearest road (1: 200-300 m; 2: 100-200 m; 3: 100-50 m; and 4: $<50 \mathrm{~m}$ ). The agreement between the PM concentration field and traffic density class for each school situated within a distance of $300 \mathrm{~m}$ from the road was 
evaluated empirically. According to this analysis, we considered that the higher the disagreement among the exposure proxy classes, the lower the agreement between the models.

\section{RESULTS}

\section{Proximity Analysis}

Of the total number of 251 schools analysed, 208 (86\%) were found to be within $300 \mathrm{~m}$ of the main roads with various levels of traffic. The rest was at greater distances and so omitted from the analysis. On average, the schools were exposed to traffic density of over 17 thousand cars per day. The average distance of schools from the nearest main road was $128 \mathrm{~m}$ (Table 1).

The majority of 141 schools out of the 208 schools (about $68 \%$ ) were located on the streets with moderate traffic up to 20,000 cars per day, while 67 schools (32\%) were exposed to high traffic density over 20,000 cars per day (Fig. 1). Potential high exposure to ambient pollution based on the nearest distance criteria (i.e. schools situated below less than $100 \mathrm{~m}$ from main roads) was attributed to $41 \%$ of schools. According to the $\mathrm{PM}_{10}$ concentration field model, $35 \%$ of school buildings were situated in locations with predicted annual average $\mathrm{PM}_{10}$ concentrations of $30 \mu \mathrm{g} / \mathrm{m}^{3}$ or higher.

\section{Comparisons of the Models}

For the set of 208 schools calculated correlation coefficient between the distance of the school building from main roads and the predicted annual $\mathrm{PM}_{10}$ concentration field related to school location was rather low but statistically significant $(\mathrm{r}=-0.381$, $\mathrm{p}<0.05$ ). It suggested that the closer the school to a main road, the higher the probability of upper particulate pollution in the school surroundings. The correlation between the traffic density attributed to each school building and the predicted annual $\mathrm{PM}_{10}$ concentration field, in which the school building is located, was for the same set of 208 schools even lower and not statistically

Table 1. Descriptive statistics of the basic proximity and traffic values

\begin{tabular}{|l|c|c|c|c|c|}
\hline & Average & SD & Median & Min & Max \\
\hline $\begin{array}{l}\text { Distance } \\
\text { (m) }\end{array}$ & 128 & 76 & 116 & 9 & 299 \\
\hline $\begin{array}{l}\text { Traffic } \\
\text { (cars/day) }\end{array}$ & 17,444 & 13,078 & 14,876 & 1,100 & 126,800 \\
\hline
\end{tabular}

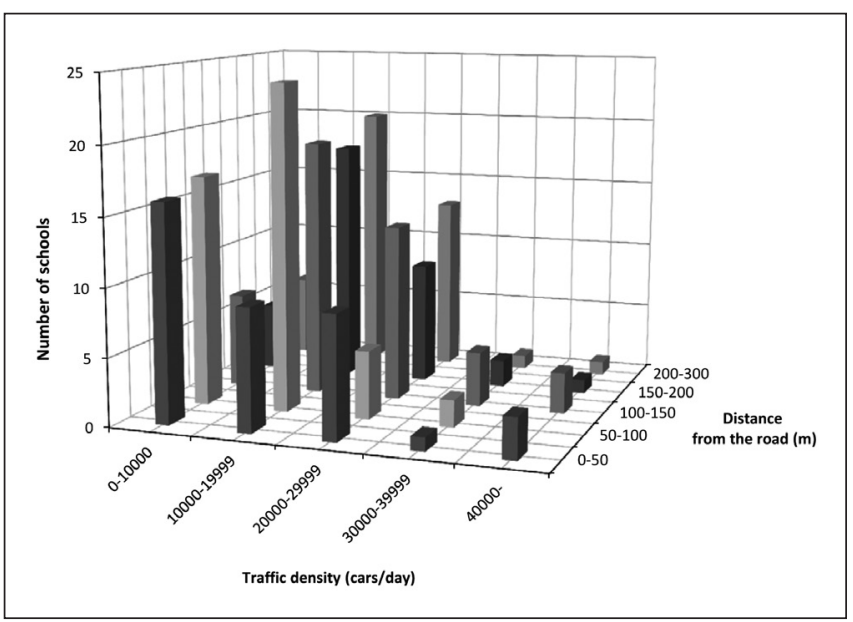

Fig. 1. Proportion of schools exposed to various traffic densities within a distance of $300 \mathrm{~m}$ of major roads in Prague.

significant $(r=0.124, p<0.05)$, only roughly suggesting that the higher the traffic density in the proximity less than $300 \mathrm{~m}$ to the nearest main road, the higher the predicted ambient particulate pollution. The multiple regression analysis showed that the independent variables (distance and traffic density) explain together only about $17 \%$ of the variability of the dependent variable $\left(\mathrm{PM}_{10}\right.$ concentration) (Table 2).

The empirical analysis of accord between the categories of exposure (traffic density and distance from the nearest road) and the category of the $\mathrm{PM}_{10}$ field of annual concentration revealed a very good accord ( 0 deviation from the same class) in about one third of the schools and also a reasonable accord (deviation by one class) in slightly less than half of the 208 analysed schools (Fig. 2). In fact, 80 schools revealed very good accord ( 0 deviation) between the distance and the $\mathrm{PM}_{10}$ field class. Also 68 schools proved good accord between the traffic density and the $\mathrm{PM}_{10}$ field class. However, only 26 schools showed good accord ( 0 deviation) between density- distance- $\mathrm{PM}_{10}$ field class.

We also calculated for all schools the average deviation between the individual classes of $\mathrm{PM}_{10}$ concentration fields and the two exposure proxies (distance of the school from main road and traffic density in the school proximity). The lowest average deviation was found between the second class of $\mathrm{PM}_{10}$ field $(20-25 \mu \mathrm{g} /$ $\mathrm{m}^{3}$ ) for both of the ambient exposure indicators, while the highest deviation was found between the fourth $\mathrm{PM}_{10}$ pollution class $\left(30-40 \mu \mathrm{g} / \mathrm{m}^{3}\right)$ and for both of the ambient exposure indicators, with the traffic density indicator revealing higher disagreement (Table 3).

Table 2. Multiple linear regression analysis ${ }^{1}$ results showing the association of distance and traffic density with the predicted average ambient annual $P M_{10}$ concentration fields at the school location $\left(N=208, R^{2}=0.171\right)$

\begin{tabular}{|l|c|c|c|c|}
\hline & $\begin{array}{c}\text { Unstandardized coefficient } \\
(\beta)\end{array}$ & $\begin{array}{c}\text { Standardized coefficient } \\
(\beta)\end{array}$ & p value & $95 \% \mathrm{Cl}$ for $\beta$ \\
\hline Constant & 28.9 & & $<0.001$ & $27.4 ; 30.3$ \\
\hline Distance to road & -0.026 & -0.396 & $<0.001$ & $-0.034 ;-0.018$ \\
\hline Traffic density & $6.175 \mathrm{E}-05$ & 0.162 & 0.012 & $0.000 ; 0.000$ \\
\hline
\end{tabular}

${ }^{1}$ Regression equation: $y=a+b_{1} \cdot x_{1}+b_{2} \cdot x_{2}$, where $y=P M_{10}$ annual concentration; $a=$ constant; $x_{1}=$ distance; $x_{2}=$ traffic density; $b_{1}$ and $b_{2}$ are regression coefficients. $C l-$ confidence interval; $\mathrm{N}$ - number of observations (schools) included in the analysis. 
Table 3. Average deviation between the classes of ambient $P M_{10}$ concentration fields and classes of distance of the schools from the main road and classes of traffic density in the vicinity of schools in Prague

\begin{tabular}{|l|c|c|c|c|}
\hline & \multicolumn{2}{|c|}{ Distance from main road } & \multicolumn{2}{c|}{ Traffic density $^{\text {SD }}$} \\
\hline PM $_{10}$ field $^{2}$ & Average $^{1}$ & SD & Average $^{1}$ & 0.76 \\
\hline Class 1 & 0.94 & 0.94 & 1.03 & 0.63 \\
\hline Class 2 & 0.69 & 0.72 & 0.63 & 0.71 \\
\hline Class 3 & 0.78 & 0.56 & 1.10 & 0.98 \\
\hline Class 4 & 1.07 & 0.68 & 1.80 & \\
\hline
\end{tabular}

${ }^{1}$ Average values include zero (no deviation between the classes)

${ }^{2} \mathrm{PM}_{10}$ classes are defined: class $1:<20 \mu \mathrm{g} / \mathrm{m}^{3}$; class $2: 20-25 \mu \mathrm{g} / \mathrm{m}^{3} ;$ class $3: 25-30 \mu \mathrm{g} / \mathrm{m}^{3}$; class $4: 30-40 \mu \mathrm{g} / \mathrm{m}^{3}$

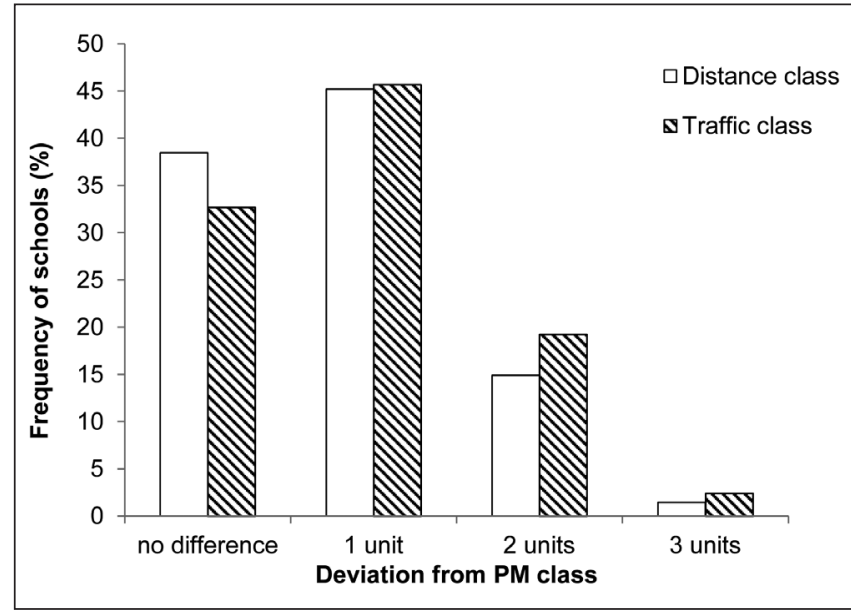

Fig. 2. Difference between classes of proximity measures (distance and traffic density classes) and the field of predicted ambient $P M_{10}$ annual concentration class at each school site (expressed as the percentage of 208 schools analysed).

\section{DISCUSSION}

Roads and schools are natural parts of city infrastructure. As urban areas develop the road network spreads and traffic density increases, it is quite challenging to keep school buildings isolated from car exhaust since neither the nearby main road nor the schools themselves can be easily relocated. Some schools elsewhere have erected noise and pollution barriers to mitigate some of these problems. The paper can benefit from mentioning possible risk mitigation strategies for schools in the highly impacted study areas. Because of their proximity to streets and roads in cities school buildings and their users (children and teachers) are continually exposed to increasing concentrations of traffic related pollutants (12).

The ambient concentration estimates (such as those determined by dispersion models and fixed-site monitors) are not truly representative of the $\mathrm{PM}_{10}$ concentrations actually breathed by school children and teachers. $\mathrm{PM}_{10}$ concentrations inside schools tend to be lower than the outdoor (ambient) concentrations. Students and teachers spend about two thirds of each school day at locations other than the school.

Various studies have attributed the label "at risk" to various proximity measures, from $100 \mathrm{~m}$ (18) to $500 \mathrm{~m}$ (19). Some studies include even shorter distances as $75 \mathrm{~m}$ (17); some even longer as 3,000 $\mathrm{m}$ (15). We selected the upper limit for our proximity analysis at $300 \mathrm{~m}$. Our decision has been inferred from the results presented by Karner et al. (20), who used data from 1983 to 2007 reported in 37 different roadside monitoring studies, encompassing more than 600 air pollutant concentration measurements collected at various distances from roads. They found that most pollutants decay to background levels within $160-800 \mathrm{~m}$ of the edge of the road. With respect to traffic density, adverse health effects were reported for traffic counts starting at about 25,000 vehicles/day $(19,21)$.

If we classify that the school buildings are in the high risk category when they are situated less than 100 metres from traffic, and in the low risk category when they are located at a distance of $100-300 \mathrm{~m}$ or more, then about $42 \%$ of Prague elementary schools fall within the high risk, and 58\% within the low risk categories, respectively. Applying similar measure to traffic density, where the border line is 25 thousand cars/day, then only $15 \%$ of schools are considered to be in the high risk group from traffic sources.

According to the World Health Organization (WHO), the body of information on long-term health effects due to ambient particulate matter is still smaller than in short term effects. However, the adverse health effects of PM may be seen in children and adults at annual average $\mathrm{PM}_{10}$ concentrations of $30 \mu \mathrm{g} / \mathrm{m}^{3}$ (or even below). That is why the WHO target guideline was set at $20 \mu \mathrm{g} / \mathrm{m}^{3}$ (22). Considering that exceeding the predicted annual $\mathrm{PM}_{10}$ concentration field of $30 \mu \mathrm{g} / \mathrm{m}^{3}$ poses a high risk then almost $35 \%$ of schools in our study may be considered as in the high risk group from traffic air pollution.

$\mathrm{Wu}$ and Battermann (14) found that in Detroit about 10\% (between $5-15 \%$ for various counties) of schools are close (within a distance of $<150 \mathrm{~m}$ ) to busy roads. However, the traffic density definition of "busy roads" in their work was much higher $(>50,000$ cars/day) than the density used in our study and also suggested by Edwards et al. (19) and Wjst et al. (21). Similarly Green et al. (13) studied proximity of schools to major roads in California. The authors showed that statewide, $2.3 \%$ of schools were located within $150 \mathrm{~m}$ of high-traffic roads $(\geq 50,000$ vehicles/day) and $7.2 \%$ were within $150 \mathrm{~m}$ of medium-traffic roads (25,000-49,999 vehicles/day). Amram et al. (17) studied proximity of public elementary schools to major roads in ten Canadian urban areas. Across all cities included in analysis they discovered $16.3 \%$ of schools located within $75 \mathrm{~m}$ of a major road (with wide variability between cities). According to Appatova et al. (16), who studied the health risk of students attending schools near major roadways in nine large Metropolitan Statistical Areas of the USA, over $30 \%$ fell within $400 \mathrm{~m}$ of a major roadway and over $10 \%$ of the schools were within $100 \mathrm{~m}$.

All the studies cited above recorded lower percentage of schools at high risk (in a distance of about $100 \mathrm{~m}$ from a main 
road) than we found in our study. The main reason for this findings may be the fact that a high number of schools in Prague (and presumably in other traditionally built cities in Europe) are situated in street canyons, where buildings are located very close to the road edges. When we located our schools on aerial maps according to their addresses, we found that $13 \%$ of the school buildings were located in the historical centre of the city, 53\% in the inner city quarters (most of which are built as a network of street canyons), $22 \%$ in the outer city where streets are wider with green areas, and $12 \%$ in the periphery with loosely arranged apartment blocks or individual houses.

To date, majority GIS based proximity models have included two variables as proxies of risk from, or exposure to, traffic related air pollutants - distance of the school from streets/roads and car counts on these streets/roads. Using the GIS tools enables researchers to evaluate large areas (cities, counties districts) for which it is practically impossible to obtain detailed air quality data based on measurements of a sufficient number of fixed-site monitors (FSM). Because of the very dense national network of automated fixed site monitors in Prague (17 FSMs) and frequent car counts, it was possible to construct a GIS layer with relatively accurate estimates of annual $\mathrm{PM}_{10}$ concentrations.

With this capability we analysed to what extent the proxies (indirect measures of exposure) are in accord with $\mathrm{PM}_{10}$ concentration fields modeled on the basis of real measurements. We found out that only about one third of both variable classes are in accordance with that of the $\mathrm{PM}_{10}$ concentration field. In many other aspects, the proximity measure appeared to be more consistent with the $\mathrm{PM}_{10}$ field than the traffic density measure. The main problem we see is the varying land use of European cities, where schools are situated in a variety of surroundings.

As mentioned above, traffic of relatively low densities in street canyons may built up relatively high concentrations of particulate matter. In more open areas (namely on peripheries of cities), the concentrations are likely to rapidly decrease with the distance from the source (20). Another source of bias may be the fact that the PM fields modeling accounts for pollutants from all principal urban emission sources, including traffic and heating, as well as long range transport and meteorological factors. The proximity models do not consider other sources than traffic. Moreover, model may be limited by various factors. First of them is the inaccuracy of geocoding caused by converting street addresses into spatial data displayed as features on a map. Roads and schools are visualized as simple lines and points instead of polygons in vector model. Secondly, we assumed data rounding in databasis we had obtained from other entities. The traffic data collection did not include the entire road network of Prague. Nevertheless, the most important sections were included.

On the basis of our findings that the indirect method of estimating exposure showed significant number of schools exposed to pollution from traffic, we decided to add another layer to our model showing the air pollution in different way. The places with poor air quality were detected above the field of air pollution concentrations on ATEM model. We expected that outputs of the model of PM concentration (direct method air quality's prediction) would be in accordance with the results of the analysis of proximity (indirect method).

We found out variations in results of the two mentioned models. By empirical calculation based on frequency of occurances be- tween two methods we could confirmed that schools located near busy roads lie in the field of higher concentrations of $\mathrm{PM}_{10}$. The prediction is rather relevant for schools located up to $150 \mathrm{~m}$ from the traffic then for those located in longer distances (150-300 m).

However, the linear relation between traffic density and $\mathrm{PM}_{10}$ concentration model was not confirmed. It is caused by other variables affecting the spread of contamination, e.g., adverse weather and meteorological conditions, the effect of street canyons, terrain disparities, or the rate of smooth running traffic.

In general, modeling of ambient $\mathrm{PM}_{10}$ concentrations in complex urban airsheds is not only difficult but likely to be inaccurate. Moreover, ambient $\mathrm{PM}_{10}$ monitoring measurements are also highly spatially and temporally variable, hampering reliable kriging or GIS interpolation of such data. Air pollution model, which we used in analysis, comprised only calculated and approximated data. Model belongs to the Gaussian dispersion models not considering flow deformations in the horizontal sphere. Also model is not suitable for measurements in street canyons or at very low wind speeds. Based on this knowledge, for further research we suggest comparing results of proximity analysis with model developed only on measured concentrations of ambient pollutants. Although we made effort to work with GIS map output of measured data, which is produced by the Czech Hydrometeorological Institute, we did not obtained that data.

Comparation of proximity analysis results with outputs from field of $\mathrm{PM}_{10}$ concentration revealed that both methods are suitable for predicting possible adverse health effects on children exposed to traffic air pollution during the stay at schools.

\section{CONCLUSIONS}

The results of our research determinated that almost $80 \%$ of Prague schools are situated in close proximity to roads exhibiting high traffic loads. Both methods showed good agreement in the number (proportion) of schools at risk to exposures from high ambient levels of $\mathrm{PM}_{10}$ concentrations. However, we found significant differences in the locations of schools at risk evaluated by the two methods. We suggest that further attention should be paid to cases where urban areas have specific arrangements (street canyons vs. loosely packed buildings). We recommend that results from other similar proximity based traffic pollution studies should be treated with caution before they are used as a part of risk based decision-making process.

\section{Acknowledgements}

The project was supported by the Czech Ministry of Education, Youth and Sports grant NPVII: No. 2B08077. We would like to thank the Prague Municipality, the Czech Ministry of Education, Youth and Sports and the ATEM Company for providing the data.

The article is dedicated to the memory of prof. RNDr. Martin Braniš, CSc., one of the most remarkable Czech environmental scientist, who passed away on 27th September 2013. Professor Braniš was a Czech naturalist, zoologist, longtime conservationist, engaged environmentalist and highly respected university lecturer. In recent years his research interest was focused on air quality, especially the quality of the indoor environment. 


\section{REFERENCES}

1. Stieb DM, Judek S, Burnett RT. Meta-analysis of time-series studies of air pollution and mortality: effects of gases and particulates and the influence of cause of death, age and season. J Air Waste Manag Assoc. 2002 Apr;52(4):470-84.

2. Pope CA 3rd., Burnett RT, Thurston G, Thun M, Calle EE, Krewski D, et al. Cardiovascular mortality and long-term exposure to particulate air pollution: epidemiological evidence of general pathophysiological pathways of disease. Circulation. 2004;109(1):71-7.

3. Janssen NA, de Hartog JJ, Hoek G, Brunekreef B, Lanki T, Timonen $\mathrm{KL}$, et al. Personal exposure to fine particulate matter in elderly subjects: relation between personal, indoor and outdoor concentrations. J Air Waste Manag Assoc. 2000;50(7):1133-43.

4. Wheeler AJ, Williams I, Beaumont RA, Hamilton RS. Characterisation of particulate matter sampled during a study of children's personal exposure to airborne particulate matter in a UK urban environment. Environ Monit Assess. 2000;65(1):69-77.

5. Sarnat JA, Koutrakis P, Suh HH. Assessing the relationship between personal particulate and gaseous exposures of senior citizens living in Baltimore, MD. J Air Waste Manag Assoc. 2000 Jul;50(7):1184-98.

6. Harrison RM, Thornton CA, Lawrence RG, Mark D, Kinerslay RP, Ayers JG. Personal exposure monitoring of particulate matter, nitrogen dioxide, and carbon monoxide, including susceptible groups. Occup Environ Med. 2002; 59(10):671-9.

7. Liu LJ, Box M, Kalman D, Kaufman J, Koenig J, Larson T, et al. Exposure assessment of particulate matter for susceptible populations in Seattle. Environ Health Perspect. 2003;111(7):909-18.

8. Schwartz J. Air pollution and children's health. Pediatrics. 2004 Apr;113(4 Suppl):1037-43.

9. Salvi S. Health effects of ambient air pollution in children. Paediatr Respir Rev. 2007;8(4):275-80.

10. Bennett WD, Zeman KL. Deposition of fine particles in children spontaneously breathing at rest. Inhal Toxicol. 1998;10(9):831-42.

11. Gauderman WJ, Avol E, Gilliland F, Vora H, Thomas D, Berhane K, et al. The effect of air pollution on lung development from 10 to 18 years of age. N Engl J Med. 2004;351(11):1057-67.
12. Janssen NA, Hoek G, Harssema H, Brunekreef B. Childhood exposure to PM10: relation between personal, classroom, and outdoor concentrations. Occup Environ Med. 1997;54(12):888-94.

13. Green RS, Smorodinsky S, Kim JJ, McLaughlin R, Ostro B. Proximity of California public schools to busy roads. Environ Health Perspect. 2004;112(1):61-6.

14. Wu YC, Batterman SA. Proximity of schools in Detroit, Michigan to automobile and truck traffic. J Expo Sci Environ Epidemiol. 2006;16(5):45770 .

15. Chakraborty J, Zandbergen PA. Children at risk: measuring racial/ethnic disparities in potential exposure to air pollution at school and home. $\mathrm{J}$ Epidemiol Community Health. 2007;61(12):1074-9.

16. Appatova AS, Ryan PH, LeMasters GK, Grinshpun SA. Proximal exposure of public schools and students to major roadways: a nationwide US survey. J Environ Plann Manag. 2008;51(5):631-46.

17. Amram O, Abernethy R, Brauer M, Davies H, Allen RW. Proximity of public elementary schools to major roads in Canadian urban areas. Int $\mathrm{J}$ Health Geogr. 2011 Dec 21;10:68.

18. van Vliet P, Knape M, de Hartog J, Janssen N, Harssema H, Brunekreef B. Motor vehicle exhaust and chronic respiratory symptoms in children living near freeways. Environ Res. 1997; 74(2):122-32.

19. Edwards J, Walter S, Griffiths RK. Hospital admissions for asthma in preschool children: Relationship to major roads in Birmingham, United Kingdom. Arch Environ Health. 1994;49(4):223-7.

20. Karner AA, Eisinger DS, Niemeier DA. Near-roadway air quality: synthesizing the findings from real-world data. Environ Sci Technol. 2010;44(14):5334-44.

21. Wjst M, Reitmeir P, Dold S, Wulff A, Nicolai T, von Loeffelholz-Colberg $\mathrm{EF}$, et al. Road traffic and adverse effects on respiratory health in children. BMJ. 1993;307(6904):596-600.

22. WHO Air quality guidelines for particulate matter, ozone, nitrogen dioxide and sulfur dioxide: summary of risk assessment. Global update 2005. Geneva: World Health Organization; 2006.

Received October 27, 2014 Accepted in revised form August 18, 2015 